\title{
Pengalaman dan Pandangan Khalayak Pegiat Sinema Non- Produksi Terkait Teknologi 3D Sebagai Pendukung Saluran Komunikasi Film
}

\author{
Shadia Imanuella Pradsmadji, Irwansyah \\ Universitas Indonesia \\ Jl. Salemba Raya No. 4, Jakarta Pusat \\ shadia.imanuella@ui.ac.id,dr.irwansyah.ma@gmail.com
}

Masuk tanggal : 26-05-2019, revisi tanggal : 16-19-2019, diterima untuk diterbitkan tanggal : 23-09-2019

\begin{abstract}
The technological development within the audiovisual industry has provided the audience with a viewing experience that is increasingly becoming more and more tangible, including in the film industry. One of the developing technologies is the $3 D$ cinema. The $3 D$ cinema emerges in hopes of delivering a stunning and memorable experience for its audience, but the mixed response from the audience, as well as the neverending development of technology, question 3D's position on offering a new experience and supporting film as a communication channel. By using the descriptive phenomenology method, this research focuses on the experience and perception of non-production film people towards $3 D$ in supporting film as a communication channel. This research aims to look on how the informants, who are not production people and are people directly involved in the exhibition and appreciation aspects of cinema, perceive and experience film in the 3D format, as well as 3D's position in the film and audiovisual industry now and in the future. The result shows that even though $3 D$ is acknowledged as a novelty and a technological leap, it does not always add something to the viewing experience, and has even become obsolete.
\end{abstract}

Keywords: 3D film, non-production film people, experience, communication channel

\begin{abstract}
Abstrak
Perkembangan teknologi dalam industri audiovisual memberikan khalayak pengalaman menonton yang semakin lama terasa semakin dekat dengan kenyataan, tak terkecuali dalam industri perfilman. Salah satu teknologi yang berkembang tersebut adalah sinema 3D. Kehadiran sinema 3D diharapkan dapat memberikan pengalaman yang menakjubkan dan berkesan bagi khalayaknya, namun penerimaan khalayak yang beragam, selain juga teknologi yang semakin berkembang, menjadi pertimbangan apakah 3D memang benarbenar memberikan pengalaman baru dan mendukung film sebagai saluran komunikasi. Penelitian ini menggunakan metodologi fenomenologi deskriptif, penelitian ini berfokus pada pengalaman dan pandangan pegiat sinema non-produksi terhadap sinema 3D sebagai pendukung saluran komunikasi film. Tujuan penelitian adalah untuk melihat bagaimana para informan, yang bukan berasal dari produksi film dan sebagai orang yang terlibat langsung dalam ekshibisi dan apresiasi sinema, memandang dan mengalami teknologi 3D. Para informan menceritakan pengalaman film mereka, pengalaman mereka ketika menonton film dalam format 3D, serta posisi teknologi 3D dalam industri film dan audiovisual di masa kini dan di masa yang akan datang. Hasil menunjukkan bahwa biarpun 3D dianggap sebagai sesuatu yang baru dan juga diakui sebagai bentuk dari
\end{abstract}


lompatan teknologi, 3D tidak selalu menambah sesuatu terhadap pengalaman menonton dan bahkan kini sudah mulai ditinggalkan.

Kata Kunci: film 3D, pegiat film non-produksi, pengalaman, saluran komunikasi

\section{Pendahuluan}

Teknologi yang semakin maju dari masa ke masa telah memengaruhi gaya dalam mengkonsumsi media, tidak terkecuali dalam ranah audiovisual. Audiovisual sendiri adalah interaksi dari musik, suara dan gambar (Robertson, 2015). Terdapat dua pemaknaan akan audiovisual oleh dua sutradara film ternama, yaitu Sergei Eisenstein asal Rusia yang melihat audiovisual merupakan bentuk dari batas ekstrem pengungkapan diri dalam kerja kreatif, serta Pier Paolo Pasolini asal Italia yang melihat bahwa teknik audiovisual apapun landasan dasarnya ada pada subjektivitas sang seniman-kedua hal ini sebenarnya secara konseptual sama (Robertson, 2015). Secara biologis sendiri, dalam kaitannya dengan audiovisual, modalitas rangsangan yang berbeda-beda mampu diintegrasikan oleh manusia untuk menciptakan persatuan persepsi yang menjadi komponen dasar dari kognisi dan perilaku berdasarkan indra (Teder-Sälejärvi, McDonald, Di Russo, \& Hillyard, 2002). Rangsangan gelombang auditori dan visual diterima oleh tubuh manusia, di mana otak kemudian memprosesnya, baik secara terintegrasi maupun secara terpisah, tergantung sumbernya (TederSälejärvi et al., 2002).

Sekarang ini, semakin banyak muncul medium audiovisual baru yang belum pernah ada pada masa-masa sebelumnya dan semakin banyak pula medium audiovisual yang sudah ada sejak masa-masa sebelumnya berkembang seiring dengan perkembangan teknologi, menjadi lebih canggih, populer dan terintegrasi. Salah satu medium audiovisual yang kini populer, relatif mudah diakses dan banyak dijumpai dalam kehidupan sehari-hari adalah sinema atau film. Sebagai karya seni, sinema memiliki kemampuan untuk memberikan hiburan, pengetahuan dan pesan (Toni \& Fajariko, 2018). Meski demikian, sinema tidak hanya dianggap sebagai karya seni, namun juga pencapaian teknologi. Sebagai medium audiovisual yang telah lama hadir, perkembangan sinema khususnya dari sisi teknologi tidak berhenti bahkan sampai sekarang.

Sinema lahir pada 1890-an di era Revolusi Industri Kedua, di mana pada masa tersebut juga banyak penemuan-penemuan teknologi lahir, seperti telepon, fonograf dan mobil (Thompson \& Bordwell, 2010). Seperti halnya penemuanpenemuan tersebut, sinema merupakan teknologi yang menjadi dasar dari sebuah industri besar, sekaligus juga bentuk hiburan baru dan medium seni baru (Thompson \& Bordwell, 2010). Sinema juga turut mengalami perkembangan seiring dengan berkembangnya teknologi, dari yang tadinya berdurasi pendek, bisu dan hitam putih, sampai akhirnya berdurasi panjang, bersuara dan berwarna. Bahkan perkembangan teknologipun sempat mengancam keberadaan sinema melalui popularitas televisi yang menawarkan khalayak pengalaman audiovisual di rumah tanpa harus bepergian. Pada 1952 ketika sinema akhirnya menyesuaikan dirinya dengan gaya menonton layar kecil di televisi, memproyeksikan gambar 
Shadia Imanuella Pradsmadji, Irwansyah: Pengalaman dan Pandangan Khalayak Pegiat Sinema Non-Produksi Terkait Teknologi 3D Sebagai Pendukung Saluran Komunikasi Film

menjadi lebih besar, dalam dan lebarpun sekali lagi memunculkan interaksi khalayak dan memperbarui pengalaman menonton sebagai sebuah peristiwa di sebuah tempat tertentu, di mana hal ini merupakan sesuatu yang tidak bisa ditiru oleh televisi (Zone, 2012). Bioskop menjadi tempat spesial seperti pada awal mula kemunculannya (Zone, 2012).

Salah satu teknologi yang hadir dalam sinema adalah gambar stereoskopik atau tiga dimensi (selanjutnya akan disebut 3D). 3D menghasilkan persepsi ruang tiga dimensi dengan cara menampilkan gambar kembar dengan perbedaan halus ke mata kiri dan kanan penonton melalui teknologi polarisasi (Jones, 2015). Ciri khas dari teknologi 3D adalah adanya efek visual timbul dari layar. Ilusi visual tersebut muncul akibat kreasi teknologi yang menimbulkan kesan adanya kedalaman (Jackman, 2015). Permainan kedalaman visual ini yang bisa membuat khalayak ketika duduk di bioskop menonton film 3D dengan menggunakan kacamata 3D terlihat seperti mengangkat tangan mereka untuk mencoba meraih gambar atau menjadi tersentak akibat lemparan benda-benda dari layar (Ross, dalam Jackman, 2015). Tujuan dari 3D adalah untuk memunculkan kesan yang lebih realistis dalam pengalaman khalayak ketika menonton film.

Gambaran besar soal realisme dalam sinema pertama kali disinggung oleh André Bazin, seorang pengkaji film berkebangsaan Prancis pada masa $L a$ Nouvelle Vague (Gerakan Baru Prancis). Bazin melihat perkembangan teknologi sinema yang sangat pesat memiliki kaitan dengan upaya untuk mencetuskan konsep "sinema total". Sebagai seseorang yang benar-benar merasakan hidup pada era 1950-an, Bazin turut menyaksikan secara langsung perkembangan teknologi yang membuat media berevolusi di masa tersebut. Bahkan Bazin kemungkinan diduga telah memperkirakan kembalinya 3D dalam sinema kontemporer serta kemunculan teknologi audiovisual Virtual Reality (VR) jauh sebelum masanya (Joret, 2016), meski Bazin sendiri wafat tidak terlalu lama sejak ia mencetuskan konsep sinema total sehingga ia tidak bisa menyaksikan perkembangan teknologi sinema yang menjadi semakin canggih pada dekadedekade selanjutnya. Konsep sinema total sendiri menyatakan bahwa tujuan dari sinema adalah untuk mewujudkan simulasi sepenuhnya atas dunia, menjadikannya semakin lama semakin nyata. Bazin menganggap sinema total adalah sebuah "mitos" (Bazin, 1967). Bazin menyatakan bahwa jika asal-usul dari setiap seni menunjukkan sesuatu terkait sifatnya, maka seseorang dapat secara sah menganggap bahwa film bisu dan bunyi sebagai tahap perkembangan teknis yang sedikit demi sedikit berusaha menjadikan kenyataan dari mitos aslinya (Bazin, 1967). Dasar sesungguhnya dari sinema ada dalam imajinasi sedikit orang di abad ke-19-para penemu sinema-dalam upaya untuk meniru kenyataan. Setiap perkembangan dalam sinema harus secara paradoks membuat sinema menjadi semakin dekat dengan asal-usulnya. Sederhananya, sinema bahkan belum ditemukan (Bazin, 1967). Hal ini karena manusia masih terus berupaya untuk mengembangkan sinema agar semakin dekat dengan dunia nyata. Meski demikian, Bazin juga tidak memperkirakan bahwa sinema akan bersifat abadi dan mengingatkan pembacanya untuk tidak terlalu turut campur dalam detil-detil masalah untuk melihat kondisinya secara menyeluruh. Selain itu, bagi Bazin, aspek komunikasi dalam sinema merupakan sesuatu yang sangat penting. Bazin 
menuliskan konsep sinema merupakan sebuah bahasa: sinema adalah sistem komunikasi yang menyiratkan atau mengharuskan pesannya diterima oleh khalayaknya (Joret, 2016).

Merujuk pada pernyataan Bazin bahwa film adalah sistem komunikasi yang menyampaikan pesan untuk diterima oleh khalayak, maka film dapat dilihat dengan model komunikasi S-M-C-R (Berlo, 1960). Dalam model komunikasi Berlo yang sendirinya dikembangkan dari model Shannon dan Weaver, komunikasi terdiri dari empat elemen, yaitu sumber atau source, pesan atau message, saluran atau channel dan penerima atau recipient. Sumber akan menyandi atau encode pesan yang disampaikan melalui saluran kepada penerima, di mana penerima akan membaca sandi atau decode pesan tersebut. Elemen pesan dalam model komunikasi Berlo melihat bagaimana kelima indra manusia menjadi saluran untuk arus komunikasi dan bagaimana kelima indra tersebut memengaruhi efektivitas salurannya. Dalam hal ini, teknologi 3D mendukung penyampaian pesan melalui medium film sebagai salurannya, khususnya dalam elemen indra penglihatan para penontonnya. Penonton yang menonton film dalam format 3D akan mengalami cara penerimaan pesan yang berbeda dibanding yang menonton film yang sama namun tidak dalam format 3D karena salurannya telah ditekankan dengan teknologi tersebut.

Jika kembali pada pernyataan Bazin soal sinema dan realisme, dalam upayanya menghadirkan realisme, teknologi 3D identik dengan "immersion", atau yang secara harfiah terjemahannya dalam Bahasa Indonesia berarti "celup". Konteks immersion berarti bahwa 3D memberikan rasa seakan-akan penonton masuk dan berada di dalam film. Dimensi-dimensi indrawi dan perwujudan dalam pengalaman menjadi sentral dalam penyebaran istilah immersion (Jackman, 2015). Tidak sulit untuk melihat sinema 3D, sebuah medium yang didasarkan pada keterlibatan sensorik dan proprioseptif, menjadi terasosiasi dengan istilah immersion dalam industri film ketika keterlibatan khalayak yang dimaksud merupakan sesuatu yang berbeda; bukan saja hanya keterlibatan mental, melainkan juga keterlibatan dengan cara mengalami sendiri (Jackman, 2015). Unsur keterlibatan yang dimunculkan dalam sinema 3D ini memberi kesan pengalaman menonton yang lebih realistis bagi khalayak.

Konsep sinema 3D sebenarnya sudah ada sejak awal mula sinema muncul. Pada masa kejayaannya yang kedua, yaitu 2000-an sampai 2010-an, perkembangan teknologi 3D yang bertujuan untuk meningkatkan pengalaman menonton tidak berhenti hanya sampai di situ saja. Untuk semakin melibatkan khalayaknya dan memberikan pengalaman yang mendalam, kini mulai ada filmfilm yang rilis dan studio-studio bioskop yang hadir dalam format 4D. Nilai jual dari sinema 4D berdasarkan pada spektakel, mengedepankan teknologi pertunjukan yang menekankan sifat indrawi dari pengalamannya (Zone, 2012). 4D melibatkan gerakan dan efek-efek lingkungan khusus, termasuk gerakan kursi (atas/bawah, kiri/kanan, depan/belakang), getaran kaki dan punggung yang dikenal sebagai ticklers, proyeksi tiupan angin, kabut dan kilat, pelepasan baubauan (mulai dari aroma di pegunungan sampai aroma bubuk mesiu), bahkan sampai simulasi hujan badai, salju dan ledakan udara-semuanya disesuaikan dengan adegan dan cerita yang sedang tayang di layar (Yecies, 2016). 
Shadia Imanuella Pradsmadji, Irwansyah: Pengalaman dan Pandangan Khalayak Pegiat Sinema Non-Produksi Terkait Teknologi 3D Sebagai Pendukung Saluran Komunikasi Film

Sederhananya, pemutaran film panjang dalam format 4D menawarkan kepada khalayak pengalaman menonton unik yang tidak bisa mereka akses melalui telepon seluler ataupun di rumah mereka (Yecies, 2016). 4D sendiri merupakan teknologi kinestetik, bukan visual. Secara visual, bioskop-bioskop dengan teknologi 4D dapat memproyeksikan film-filmnya dalam format 2D maupun 3D. Adanya film 3D yang ditayangkan dengan teknologi 4D menjadi cara untuk semakin melibatkan penonton dalam pengalaman menonton film tersebut.

Pada dasarnya, teknologi sinema 3D dan 4D diharapkan dapat menghadirkan pengalaman yang menyenangkan bagi khalayaknya. Seringkali pengalaman menyenangkan sebagai respon dari konsumsi media dideskripsikan sebagai hiburan atau kenikmatan, di mana kedua istilah ini sering digunakan secara tumpang tindih (Sobieraj \& Krämer, 2014). Kenikmatan diasumsikan sebagai jantung dari hiburan media (Vorderer et al., dalam Sobieraj \& Krämer, 2014), di mana kenikmatan dapat termanifestasikan dalam berbagai cara, seperti ketenangan, ketegangan, kenikmatan indrawi, sampai kesedihan (Sobieraj \& Krämer, 2014). Meski demikian, Vorderer et al. (dalam Sobieraj \& Krämer, 2014) mengusulkan bahwa model pengalaman hiburan ini perlu diuji secara empiris dalam konteks yang beragam, di mana mereka menegaskan bahwa dalam konteks media yang berbeda, kenikmatannya juga bisa bergantung pada variabel yang berbeda-beda.

Semenjak satu dekade terakhir, penayangan-penayangan 3D menjadi semakin tinggi popularitasnya (Sobieraj \& Krämer, 2014). Meski demikian, 3D tidak selalu mendapatkan penerimaan baik. Kritikus film ternama asal Amerika Serikat Roger Ebert menganggap bahwa terdapat kepercayaan yang keliru dalam menganggap 3D sebagai sesuatu yang realistis; dalam kehidupan sehari-hari manusia memang melihat dalam tiga dimensi, tetapi tidak melihat bagian-bagian dari penglihatan yang memisahkan diri dari yang lain dan melompat kepada kita, dan kita juga tidak benda-benda bergerak sebegitu lambatnya sehingga bisa melihat mereka bergerak (Ebert, 2008). Bahkan, saat ini, walaupun telah lebih dari sepuluh tahun sejak hadirnya 3D baru, teknologi ini masih tetap dalam masa transisi (Klinger, 2013). Sebagian hal yang membuat masa depan 3D menjadi tidak pasti bergantung pada statusnya sebagai teknologi asing yang sulit digunakan dan bagi sebagian sulit untuk ditonton, genre-genre fantasi dan serupa yang mendominasi asosiasinya, serta ketidakstabilannya (Klinger, 2013). Selain itu, penggunaan teknologi 3D dalam film yang tayang di bioskop memang semakin menekankan perbedaan kualitatif atas apa yang mungkin terjadi antara bioskop dan televisi, namun persaingan yang dihadapi oleh 3D di bioskop adalah rasa mendapatkan sesuatu melalui televisi secara gratis jika dibandingkan dengan kenikmatan optikalnya, serta adanya pilihan untuk menghabiskan waktu dengan cara bermalas-malasan di rumah (Tyler, dalam Zone, 2012). Tampaknya 3D bukanlah jaminan untuk menikmati sebuah pengalaman sinema dan bahwa ada prasyarat-prasyarat lain yang lebih penting dibanding teknologi penentu moda penayangan (Sobieraj \& Krämer, 2014). 
Berdasarkan pemahaman yang peneliti dapatkan dari berbagai paparan di atas, maka peneliti mengajukan pertanyaan penelitian berupa: Bagaimana khalayak yang juga pegiat sinema dalam ranah non-produksi mendeskripsikan pengalaman dan pandangan mereka terkait sinema 3D sebagai pendukung saluran komunikasi film?

Tujuan penelitian ini adalah untuk melihat bagaimana para pegiat sinema non-produksi memandang 3D dalam kaitannya sebagai teknologi pendukung saluran komunikasi film, baik secara positif maupun negatif serta bagaimana posisi 3D ke depannya sebagai teknologi pendukung saluran komunikasi film. Penelitian ini diharapkan dapat menambah khazanah pengetahuan mengenai film sebagai saluran komunikasi khususnya dilihat dari sisi non-produksi.

\section{Metode Penelitian}

Penelitian ini menggunakan metode kualitatif. Dalam penelitian kualitatif, peneliti meminjam gagasan-gagasan dan sudut pandang dari orang-orang yang diteliti dan meletakkannya dalam pengaturan alamiah yang mengalir (Neuman, 2014). Penelitian kualitatif tidak berusaha untuk menguji variabel, melainkan motif, tema, perbedaan maupun perspektif (Neuman, 2014).

Strategi penelitian yang digunakan dalam penelitian ini adalah fenomenologi deskriptif. Fenomenologi deskriptif mencoba untuk mengeksplorasi suatu fenomena berdasarkan pengalaman individu nuansa, landasan kontekstual, emosi, dan tindakan yang ditimbulkan dalam kesadaran (Christensen, Welch, \& Barr, 2017). Peneliti mencoba untuk memahami bagaimana para pegiat sinema non-produksi memaknai sinema 3D dan apa saja yang mendorong mereka untuk menikmati atau tidak menikmati teknologi tersebut khususnya sebagai nilai tambah dalam pengalaman menonton dan dalam mendukung film sebagai saluran komunikasi. Dalam upaya menggali pengalaman informan, peneliti memilih wawancara semi-terstruktur karena pertanyaan-pertanyaan yang diajukan kepada para informan menggapai aspek-aspek pengalaman yang sedang dieksplorasi, namun sifatnya yang tidak kaku membuat peneliti dapat menyesuaikan alur pertanyaan sesuai dengan pembicaraan informan (Langdridge, 2007).

Sampel untuk penelitian ini diambil secara purposif karena berguna untuk memberikan wawasan luas dan informasi yang kaya akan suatu isu atau topik. Terdapat kriteria-kriteria yang ditetapkan peneliti sebagai bagian dari langkah pemilihan informan, yaitu (1) pernah mengenyam pendidikan sinema secara formal dan kini aktif dalam kegiatan ekshibisi atau apresiasi sinema atau tidak pernah mengenyam pendidikan sinema secara formal namun aktif dalam kegiatan ekshibisi atau apresiasi sinema selama lima tahun terakhir, (2) menonton film setidaknya seminggu sekali, dan (3) pernah menonton film 3D di bioskop. Pemilihan informan memang ditetapkan secara khusus kepada mereka yang berkecimpung pada ranah ekshibisi dan apresiasi sinema, bukan ranah produksi film, karena ranah ekshibisi dan apresiasi menuntut pegiatnya untuk memerhatikan aspek-aspek yang dibutuhkan baik untuk menayangkan maupun untuk menganalisis dan menulis kritik terhadap sebuah film, sehingga pemilihan informan dari kedua bidang tersebut lebih sesuai untuk penelitian ini. 
Shadia Imanuella Pradsmadji, Irwansyah: Pengalaman dan Pandangan Khalayak Pegiat Sinema Non-Produksi Terkait Teknologi 3D Sebagai Pendukung Saluran Komunikasi Film

Berangkat dari kriteria-kriteria di atas, peneliti mewawancarai lima informan. Seluruh informan sama-sama memilki kedekatan pribadi dengan eksibisi atau apresiasi sinema dan pernah mengenyam pendidikan sinema secara formal dan kini aktif dalam bidang tersebut atau telah berpengalaman di bidang tersebut dalam jangka waktu yang panjang. Informan pertama adalah seorang pegiat pemutaran film yang telah aktif sejak 2010 dan saat ini merupakan manajer salah satu bioskop alternatif di Jakarta serta untuk sebuah situs khusus kritik dan kajian film. Informan kedua adalah seorang kritikus film yang telah aktif sejak 2008, salah satu pendiri dan redaksi dari sebuah situs khusus kritik dan kajian film serta pernah menjadi dosen film di salah satu sekolah film di Jakarta. Informan ketiga telah aktif di dunia ekshibisi film sejak 2012 dengan pertama kali berkecimpung sebagai pegiat salah satu festival film di Solo dan kini aktif sebagai pegiat pemutaran film secara independen di Jakarta. Informan keempat lulus dari salah satu sekolah film di Jakarta pada 2015 dan telah selama setahun terdaftar sebagai anggota komunitas film Singapura, di mana tujuh bulan terakhir ia berperan sebagai relawan untuk bidang program film. Informan kelima merupakan pegiat festival film khusus dokumenter sejak 2012 sekaligus juga pengkaji dan dosen film di salah satu institut di Yogyakarta.

Seluruh wawancara dilaksanakan melalui telepon, kecuali kepada informan pertama yang wawancaranya dilaksanakan secara langsung. Wawancara telepon mampu mengatasi masalah jarak antara peneliti dengan informan maupun masalah waktu yang tidak memungkinkan membuat informan bertemu secara langsung dengan peneliti. Rata-rata wawancara dengan informan memakan waktu sekitar 30 sampai 40 menit. Tidak ada kompensasi yang diberikan kepada para informan.

\section{Hasil Penemuan dan Diskusi}

Bagian ini akan menuliskan hasil yang diperoleh dari analisis kualitatif terkait pengalaman dan pandangan khalayak yang sekaligus juga pegiat sinema non-produksi untuk mengidentifikasi apa saja yang menurut para informan merupakan kunci dari pilihan mereka dalam menonton atau tidak menonton dan menikmati atau tidak menikmati sinema 3D serta apakah 3D mendukung atau tidak mendukung film sebagai saluran komunikasi.

\section{Frekuensi Menonton Film 3D}

Meski kelima informan sama-sama sering menonton film sehari-harinya, baik di bioskop maupun di tempat lain, hampir semua menyatakan bahwa mereka tidak terlalu sering menonton film 3D. Beberapa informan bahkan menyatakan jarang. Informan pertama menyatakan sudah hampir tidak pernah lagi menonton film dalam format 3D. Informan kedua menyatakan bahwa jumlah film yang ia tonton dalam format 3D, dalam bahasa informan, "bisa dihitung pakai jari." Senada dengan informan kedua, informan ketiga juga mengaku frekuensi menonton film 3D-nya bisa dihitung. Informan kelimapun menyatakan ia tidak sering menonton film 3D. Dari seluruh informan, informan keempatlah yang secara frekuensi lebih sering menonton film 3D di bioskop. 
Informan pertama dan kelima menyatakan masalah jarak yang jauh dari rumah menuju bioskop yang memiliki proyektor 3D sebagai salah satu yang menghambat mereka menonton film 3D dalam frekuensi yang lebih sering. Hampir serupa dengan informan pertama dan kelima, informan ketiga mengatakan hambatan baginya adalah karena bioskop yang memiliki proyektor 3D di daerahnya jumlahnya sangat terbatas. Informan keempat menyatakan masalah kenyamanan bagi dirinya pada saat itu menjadi pertimbangan apakah ia menonton film 3D atau tidak: dari bioskop manakah ia berada dalam jarak terdekat, apakah bioskop tersebut menayangkan film dalam format 3D atau tidak, apa jenis layarnya, apakah jadwal tayangnya sesuai dengan jadwal yang ia kehendaki, serta bagaimana dengan ketersediaan kursi di posisi tengah yang ia sebut sebagai posisi yang paling nyaman baginya. Sementara itu, berbeda dari informan-informan lainnya, informan kedua mengatakan bahwa pada dasarnya ia sendiri lebih senang menonton film-film lama yang tidak mengharuskan dirinya untuk pergi ke bioskop. Informan kedua juga langsung menyatakan bahwa dirinya memang tidak menyukai menonton film dalam format 3D.

\section{Pilihan untuk Menonton atau Tidak Menonton Film dalam Format 3D}

Informan pertama menyatakan bahwa ia tidak perlu menonton semua film dalam format 3D. Informan pertama meyakini bahwa tidak semua film yang rilis dalam format 3D perlu ditonton dalam format 3D karena ada unsur ketakjuban secara sinematik yang membuat beberapa film menjadi lebih spesial ditonton dalam 3D dibanding film lainnya. Ia menyebutkan film horor dan laga yang, dalam bahasanya, bersifat "outer world" dan tidak merefleksikan kehidupan sehari-hari sebagai contoh genre yang menurutnya cocok ditonton dalam format 3D. Penjelasan informan pertama atas pilihannya:

Format 3D... biasanya kalau itu terkait sama experience yang ditawarin sama filmnya. Misalnya kayak secara teknis dan sinematik itu kayaknya memang menakjubkan kalau pakai 3D gitu. Ya paling itu sih. Kalau misalnya, kayak nih, misalnya kan beberapa film Disney 3D, ada yang masuk sini 3D. Tapi gua nggak sebegitu pengen, kayaknya nggak terlalu sinematik untuk bisa gua... itu.

Meski sama-sama meyakini bahwa tidak perlu semua film ditonton dalam format 3D, informan kelima memiliki pandangan yang berbeda. Ia justru mengatakan akan lebih tertarik menonton film-film 3D apabila film tersebut merupakan film animasi seperti keluaran Disney dan bukan film-film bergenre pahlawan super yang menurutnya membuat ia tidak nyaman karena merasa seperti terkepung di dalam aksi-aksinya. Penjelasan informan kelima:

Aku tuh kebayang kalau nonton film Disney, kayak live action-nya Disney, itu aku ngebayangin tuh... ini pasti bakal bagus banget ya, aku seolah-olah berada di setting yang sama dengan mereka, terus objeknya bakal bergerak ke aku, terus aku kayak ada di dalam dunia itu gitu. Karena mungkin aku suka fantasifantasinya, pilihannya adalah film-film Disney, tapi bukan film-film Avengers dan Marvel dan teman-temannya itu. 
Shadia Imanuella Pradsmadji, Irwansyah: Pengalaman dan Pandangan Khalayak Pegiat Sinema Non-Produksi Terkait Teknologi 3D Sebagai Pendukung Saluran Komunikasi Film

Sementara itu, informan keempat tidak memiliki alasan spesifik dan kembali ke alasan awalnya yaitu kenyamanan di waktu dan tempat dirinya berada saat itu serta pilihan ukuran layar yang tersedia. Informan ketiga menjelaskan bahwa menonton film 3D membutuhkan ruang yang tepat karena akan menentukan sensasi saat menonton. Informan kedua menjelaskan bahwa ia pada umumnya sebisa mungkin akan menghindari pilihan 3D karena informan merasa jarak visual dengan film yang ia tonton menjadi sangat minim sehingga membuatnya kesulitan berpikir.

\section{Pandangan Menonton Film 3D (dan 4D) Sebagai Pendukung Pengalaman Menonton dan Penceritaan Film}

Meskipun seluruh informan setuju bahwa 3D memang menawarkan pengalaman menonton yang berbeda, namun para informan memiliki pandangan yang berbeda-beda mengenai pengalaman itu sendiri. Informan ketiga dan keempat memiliki pengalaman dengan 3D yang cukup unik. Informan ketiga justru merujuk pengalaman menonton film 3D di Taman Pintar Yogyakarta, yang bukan bioskop, sebagai pengalaman 3D yang paling berkesan bagi dirinya. Saat itu ia menonton sebuah film anak - yang ia lupa judulnya - di mana anak-anak yang menonton saat itu menjadi sangat interaktif. Bagi informan ketiga, Taman Pintar Yogyakarta juga berhasil menjawab persoalan ruang yang baginya adalah elemen yang krusial dalam pemutaran film 3D dan belum berhasil dijawab oleh bioskop. Penjelasan informan ketiga:

Kita ngomongin bioskop di sini, itu desainnya untuk film-film yang, ya film biasa gitu, pada umumnya. Sementara 3D-nya itu kayak dipaksakan. Bukan untuk didesain untuk film 3D. Ah... Kenapa Taman Pintar itu jadi lebih masuk buat aku? Aku di Taman Pintar dapat kursi yang pinggir juga dan mengalami sensasi yang enak waktu nonton 3D. Kenapa? Karena memang ruangnya didesain untuk 3D. Pada akhirnya lu mau nyetel apa, mau nyetel apa, kamu pakai kacamata itu, kamu punya pengalaman yang menyenangkan, gitu. Experience-nya dapet.

Lain halnya bagi informan keempat yang merasa bahwa pengalaman menonton film 3D di bioskop baginya tidak menjadi sesuatu yang istimewa, karena baginya kebanyakan film 3D hanya bersifat gimmick dan tidak memberi nilai tambah signifikan terhadap filmnya. Ia merujuk kepada wahana 3D di taman hiburan sebagai pengalaman 3D yang ia harapkan, di mana baginya film 3D di bioskop kurang berhasil menawarkan kembali pengalaman tersebut. Menurut informan keempat:

Gua 3D sih berharapnya kayak pop up gitu loh, kalau untuk depth segala macam gua nggak berasa kayak gimana banget. Gua merasa lebih ke pop up dan kayaknya kebanyakan film 3D tuh... nggak pop up gitu. Nggak kayak yang lu nonton di Disneyland atau Universal Studios gitu loh. Karena gua harapannya mungkin lebih kayak gitu ya, karena standar dulu sebelum heboh $3 D$, orang nonton $3 D$ kayak di Universal Studios, Disneyland gitu kan, jadi harapan gua ya kayak gitu. 
Sementara itu, informan pertama, kedua dan kelima menceritakan pengalaman mereka dengan film 3D di bioskop. Informan pertama merujuk pada film merujuk pada film Avatar (James Cameron, 2009) pengalaman yang paling berkesan karenanya karena ia sendiri penasaran dengan bagaimana James Cameron memanfaatkan teknologi 3D untuk penceritaan Avatar seperti yang ia baca di berita-berita dan merasa takjub dengan efek timbul yang ia lihat. Bagi informan pertama, 3D bukan hanya untuk memunculkan kesenangan estetika, namun juga teknologi, karena sinema pada awalnya pun berakar dari teknologi. meski demikian, informan pertama menambahkan bahwa sinema 3D tidak lantas secara signifikan mendukung penceritaan film dan juga merasa bahwa pengalaman ketika sedang menonton film 3D tidak kemudian membuat dirinya menjadi ingin mengetahui lebih lanjut jalan cerita filmnya.

Informan kelima merujuk pada film Coco (Lee Unkrich dan Adrian Molina, 2017) sebagai film dengan format 3D yang berkesan baginya, di mana ia merasa seperti berada di dalam satu ruang yang sama dengan para karakter dan juga merasa takjub dengan pengalaman sinematik yang ia peroleh saat itu. Informan kelima langsung merujuk pada warna yang lebih terang sebagai nilai tambah terhadap pengalaman sinematiknya. Ia menyebutkan hal ini juga karena film Coco memang sejak awalnya memiliki warna-warna yang indah, selain juga film tersebut memang menawarkan imajinasi yang melampaui kehidupan seharihari. Namun ia juga menekankan bahwa memang tidak semua film dapat menawarkan pengalaman menakjubkan ini. Menurutnya, tidak perlu semua harus menggunakan teknologi 3D untuk mendukung penceritaannya.

Berbeda dari informan pertama dan kelima yang menonton film dalam format 3D tanpa tambahan efek lain, informan kedua merujuk pada film Avengers: Endgame (Anthony dan Joe Russo, 2019) sebagai pengalaman terakhirnya menonton film dalam format 3D sekaligus juga 4DX. Meski demikian, informan kedua merasa pengalaman tersebut melelahkan karena menurutnya efek-efek tambahan dari 4DX sifatnya tidak konsisten dan tidak sesuai dengan alur cerita yang sedang ditampilkan di layar. Hal ini juga diperkuat dengan dirinya yang sudah merasa bermasalah dengan visual 3D itu sendiri. Bagi informan kedua, 3D adalah bagian dari fenomena kultural. Ia tidak menyebut 3D sebagai teknologi.

\section{Pandangan Terhadap Masa Depan 3D dan Teknologi Industri Perfilman}

Para informan melihat bahwa ke depannya, teknologi 3D akan bergeser, khususnya dengan hadirnya media-media baru yang semakin terintegrasi dengan teknologi lain sekarang ini yang sudah mulai berhasil menggeser 3D. Informan pertama melihat teknologi 3D akan bergeser dan digantikan dengan teknologiteknologi terbaru, seperti halnya sejarah sinema dari mulai film bisu hitam putih sampai bisa bersuara dan berwarna, dan merasa bahwa 3D akan bertahan untuk menjadi sesuatu yang dicari orang ketika mereka ingin bernostalgia. Informan ketiga melihat perkembangan teknologi VR akan-bahkan sudah mulaimengambil alih. Bagi informan ketiga, 3D tidak akan berjangka panjang, seperti halnya drive-in cinema sebagai contoh jenis sinema yang ia sebut berjangka pendek. Informan keempat bahkan sudah merasa bahwa 3D tidak lagi seheboh 
Shadia Imanuella Pradsmadji, Irwansyah: Pengalaman dan Pandangan Khalayak Pegiat Sinema Non-Produksi Terkait Teknologi 3D Sebagai Pendukung Saluran Komunikasi Film

satu dekade lalu ketika ia baru mulai muncul. Menurut informan keempat, semakin lama jumlah film dalam format 3D akan semakin jarang dan orang-orang akan beralih pada format premium lain seperti IMAX atau layar yang lebih besar sebagai pertimbangan dalam pilihan menonton. Tidak jauh berbeda, informan kelima melihat 3D sebagai teknologi yang sudah agak lama, di mana ia sudah mulai dipopulerkan bahkan sejak dulu ketika televisi nasional Indonesia menayangkan sinetron 3D yang para penonton menonton dengan kacamata 3D kertas. Bagi informan kelima, orang-orang akan beralih kepada tayangan mobile, selain juga beranggapan bahwa teknologi VR dan AR atau Augmented Reality akan menjadi semakin berkembang, sehingga tidak lagi berpatokan kepada 3D.

Secara khusus, informan kedua memandang perkembangan teknologi industri perfilman akan menjadi semakin jauh lagi. Ia menekankan pada personalisasi sebagai pengalaman yang ditawarkan di masa depan. Dalam hal ini, sinema tidak lagi hanya menjadi media hiburan semata, namun merupakan salah satu medium audiovisual yang sifatnya melibatkan seluruh indra manusia dan bahkan dapat digunakan untuk menjadi jembatan transaksi bisnis yang dapat disesuaikan dengan masing-masing individu. Informan kedua merujuk pada istilah "digital capitalism". Penjelasan informan kedua:

Katakanlah ini kita berandai-andai aja ya. Misalnya ada satu perusahaan yang menjual teknologi imersif, semua. Seтua itu engaged. Ya tubuh lu bakal dipasang kabel, ok. Misalnya lu mau nonton film apa, katakanlah John Wick 3. Itu kan bakbuk-bakbuk ya. Dan sepertinya lebih asik ketika semua sense lu tuh terlibat untuk itu. Bayangkan ada satu teknologi nanti yang bisa bikin lu engaged. Dan itu kan artinya kan... tubuh lu dipasangin kabel. Detak jantung lu diukur. Ini kayak gabungin VR dengan alat pengukur... smart watch. Detak jantung lu diukur. Ketika misalnya... apa ya ... alat yang sama bisa mengukur gelombang otak dan bisa merepresentasikan bau dalam film itu, lalu lu nyium bau itu lu nggak suka, bau ini lu suka, dan otak lu memproses bau, mengeluarkan gelombang, gelombang itu juga diukur, nanti ya ujung-ujungnya, misalkan itu terhubung ke Facebook. Besoknya tiba-tiba ada iklan parfum, lu suka bau ini nggak, lu suka bau itu nggak.

\section{Diskusi}

Pandangan dan pengalaman para pegiat sinema non-produksi memang berbeda-beda, namun terdapat beberapa hal yang dapat ditarik benang merahnya. Para informan umumnya setuju bahwa 3D memang memberi pengalaman yang berbeda, meski pengalaman tersebut bisa jadi positif maupun negatif tergantung kepada masing-masing informan.

Para informan menyebutkan 3D sebagai suatu teknologi imersif yang memanfaatkan indra-indra manusia dan semakin melibatkan penontonnya dengan film (Zone, 2012; Jackman, 2015). Meski demikian, keterlibatan ini tingkatannya berbeda-beda, di mana ada informan yang melihat tidak ada keterlibatan signifikan yang ia rasakan, sementara informan lain menganggap keterlibatan terus menerus sepanjang film ini dapat menimbulkan rasa lelah. Selain itu, karena sifat alamiahnya, genre-genre yang dapat menggunakan teknologi 3D juga terbatas (Klinger, 2013) karena tidak semua film membutuhkan teknologi ini dalam penceritaannya. Bahkan beberapa film 3D pada akhirnya hanya 
mengandalkan 3D sebagai gimmick. Pada akhirnya, meski 3D memang didesain untuk menawarkan kenikmatan menonton, hal ini tidak langsung menentukan pengalaman menonton menjadi lebih nikmat (Sobieraj \& Krämer, 2014).

Para informan setuju bahwa 3D kini juga sudah mulai ditinggalkan. Teknologi-teknologi baru akan mulai menggeser 3D dan menghadirkan pengalaman yang berbeda. Bahkan 3D kini juga harus bertanding dengan tayangan mobile yang dapat membuat orang lebih nyaman menonton di mana saja dan kapan saja, termasuk di rumah (Tyler, dalam Zone, 2012). Hal ini menandakan bahwa 3D hanyalah salah satu cara berbasis teknologi yang tidak akan bersifat abadi untuk mendukung film sebagai saluran komunikasi.

\section{Simpulan}

Hasil penelitian menunjukkan bahwa walaupun teknologi 3D memang menawarkan pengalaman menonton yang berbeda dan, pada beberapa film, dapat membuat penonton takjub, para pegiat sinema non-produksi tidak melihat teknologi 3D sebagai sesuatu yang sangat istimewa dan membawa nilai lebih secara signifikan terhadap pengalaman menonton mereka maupun dalam mendukung penceritaan film sebagai saluran komunikasi. Sebagian merasa 3D sudah mulai bergeser dan tidak sejaya dulu ketika pertama kali muncul, karena tidak ada lagi kebaruan yang ditawarkan. Hal ini semakin didukung oleh masingmasing orang yang bisa jadi menganggap 3D sebagai hal yang positif maupun negatif. 3D juga memiliki isu-isu teknis lainnya yang jika tidak terpenuhi tidak akan memberikan pengalaman yang maksimal.

Meski sinema 3D masih populer hingga sekarang dan masih memiliki pangsa pasar 3D, teknologi 3D akan tergantikan dan akan muncul lagi teknologiteknologi baru yang berintegrasi dengan medium-medium lain dalam industri audiovisual, tidak saja hanya sinema, dan membentuk produk-produk audiovisual baru yang akan menawarkan pengalaman-pengalaman yang semakin imersif dan pribadi kepada para penontonnya, bahkan bisa dikaitkan dengan bisnis komersial. Dengan penjelasan dari para pegiat non-produksi mengenai pandangan dan pengalaman mereka akan 3D yang banyak menawarkan wawasan baru mengenai teknologi dalam kaitannya dengan film sebagai saluran komunikasi, maka tujuan penelitian ini telah tercapai.

Peneliti mengakui bahwa penelitian ini memiliki keterbatasan. Perlu dicatat bahwa sampel diambil dari orang-orang yang memang menekuni bidang ekshibisi dan apresiasi film tidak dapat menjadi generalisasi untuk memahami pengalaman khalayak secara umum dalam memandang teknologi 3D untuk mendukung film sebagai saluran komunikasi. Selain itu, penelitian ini juga menekankan pandangan dan pengalaman dalam menonton sinema 3D, sehingga penelitian ini tidak memberikan laporan komprehensif mengenai sinema 3D dan kepuasan khalayak secara umum. Peneliti berharap bahwa penelitian ini dapat menjadi kesempatan agar dapat muncul penelitian-penelitian lanjutan yang melihat hal-hal yang belum terungkap atau teruji dari penelitian ini, seperti hubungan antara sinema 3D dan kepuasan menonton, pengalaman khalayak dari 
Shadia Imanuella Pradsmadji, Irwansyah: Pengalaman dan Pandangan Khalayak Pegiat Sinema Non-Produksi Terkait Teknologi 3D Sebagai Pendukung Saluran Komunikasi Film

sampel yang lebih luas terhadap teknologi sinema dan audiovisual lainnya, serta masa depan teknologi dan industri perfilman secara lebih rinci.

\section{Ucapan Terima Kasih}

Peneliti ingin mengucapkan terima kasih kepada rekan-rekan Cinema Poetica, Binus Film School angkatan "Focus" dan Asosiasi Pengkaji Film Indonesia (KAFEIN) atas bantuan akses bagi peneliti dalam pelaksanaan penelitian ini.

\section{Daftar Pustaka}

Bazin, A. (1967). What is Cinema? Berkeley: University of California Press.

Berlo, D. (1960). The Process of Communication. New York: Holt, Rinehart, and Winston, Inc.

Christensen, M., Welch, A., \& Barr, J. (2017). Husserlian Descriptive Phenomenology: A review of intentionality, reduction and the natural attitude. Journal of Nursing Education and Practice, 7(8), 113. https://doi.org/10.5430/jnep.v7n8p113

Ebert, R. (2008). D-minus for 3-D. Retrieved May 22, 2019, from https://web.archive.org/web/20130207230520/http://blogs.suntimes.com/eb ert/2008/08/dminus_for_3d.html

Jackman, A. H. (2015). 3-D cinema: Immersive media technology. GeoJournal, 80(6), 853-866. https://doi.org/10.1007/s10708-015-9651-5

Jones, N. (2015). Variation within Stability: Digital 3D and Film Style. Cinema Journal, 55(1), 52-73.

Joret, B. (2016). André Bazin's New Media. Screen, 57(4), 509-512. https://doi.org/10.1093/screen/hjw049

Klinger, B. (2013). Three-dimensional cinema: The new normal. Convergence, 19(4), 423-431. https://doi.org/10.1177/1354856513494177

Langdridge, D. (2007). Phenomenological Psychology: Theory, Research and Method. Essex: Pearson Education Limited.

Neuman, W. L. (2014). Social Research Methods: Qualitative and Quantitative Approaches (7th ed.). Essex: Pearson Education Limited.

Robertson, R. (2015). Cinema and the Audiovisual Imagination: Music, Image and Sound. London: I. B. Tauris.

Sobieraj, S., \& Krämer, N. (2014). Do 3D Moviegoers Enjoy Screenings More than 2D Moviegoers?-On the Impact of 3D Fantasy Movie Perception on Enjoyment. Presence, 23(4), 430-448. https://doi.org/10.1162/PRES_a_00210

Teder-Sälejärvi, W. A., McDonald, J. J., Di Russo, F., \& Hillyard, S. A. (2002). An analysis of audio-visual crossmodal integration by means of eventrelated potential (ERP) recordings. Cognitive Brain Research, 14, 106-114. https://doi.org/10.1016/S0926-6410(02)00065-4

Thompson, K., \& Bordwell, D. (2010). Film History: An Introduction (2nd ed.). New York: McGraw-Hill. Retrieved from 
http://ccuc.cbuc.cat/record=b4780028 S23*cat

Toni, A., \& Fajariko, D. (2018). Studi Resepsi Mahasiswa Broadcasting Universitas Mercu Buana Pada Film Journalism "Kill The Messenger." Jurnal Komunikasi, 9(2), 151. https://doi.org/10.24912/jk.v9i2.161

Yecies, B. (2016). Transnational collaboration of the multisensory kind: Exploiting Korean 4D cinema in China. Media International Australia, 159(1), 22-31. https://doi.org/10.1177/1329878X16640104

Zone, R. (2012). 3-D Revolution: The History of Modern Stereoscopic Cinema (1st ed.). Lexington: University Press of Kentucky. 